\title{
Preparation and Faraday effect of EuS microcrystal-embedded oxide thin films
}

\section{AUTHOR(S):}

Tanaka, Katsuhisa; Tatehata, Naoki; Fujita, Koji; Hirao, Kazuyuki

\section{CITATION:}

Tanaka, Katsuhisa ...[et al]. Preparation and Faraday effect of EuS microcrystal-embedded oxide thin films. JOURNAL OF APPLIED PHYSICS 2001, 89(4): 2213-2219

\section{ISSUE DATE:}

2001-02-15

URL:

http://hdl.handle.net/2433/39699

\section{RIGHT:}

Copyright 2001 American Institute of Physics. This article may be downloaded for personal use only. Any other use requires prior permission of the author and the American Institute of Physics. 


\title{
Preparation and Faraday effect of EuS microcrystal-embedded oxide thin films
}

\author{
Katsuhisa Tanaka ${ }^{a}$ \\ Department of Chemistry and Materials Technology, Faculty of Engineering and Design, \\ Kyoto Institute of Technology, Matsugasaki, Sakyo-ku, Kyoto 606-8585, Japan \\ Naoki Tatehata, Koji Fujita, and Kazuyuki Hirao \\ Department of Material Chemistry, Graduate School of Engineering, Kyoto University, Yoshidahonmachi, \\ Sakyo-ku, Kyoto 606-8501, Japan
}

(Received 17 April 2000; accepted for publication 13 November 2000)

EuS microcrystal-embedded $\mathrm{SiO}_{2}, \mathrm{Al}_{2} \mathrm{O}_{3}$, and $\mathrm{TiO}_{2}$ thin films have been prepared by using if sputtering method. X-ray diffraction analysis indicates that EuS microcrystal is precipitated as a single phase in $\mathrm{Al}_{2} \mathrm{O}_{3}$ and $\mathrm{TiO}_{2}$ films while precipitation of EuS is not detected in $\mathrm{SiO}_{2}$ film. Faraday effect attributable to the $4 f^{7}-4 f^{6} 5 d$ transition of $\mathrm{Eu}^{2+}$ in EuS microcrystalline phase is observed in $\mathrm{Al}_{2} \mathrm{O}_{3}$ and $\mathrm{TiO}_{2}$ films. In particular, Faraday rotation angle observed for EuS-embedded $\mathrm{TiO}_{2}$ film is large; for instance, the magnitude of Verdet constant for as-deposited $\mathrm{TiO}_{2}$ film prepared without heating of substrate during the sputtering is $0.15 \mathrm{deg} / \mathrm{cm}$ Oe at wavelength of 700 $\mathrm{nm}$. This value is larger by two orders of magnitude than those of $\mathrm{Eu}^{2+}$ - or $\mathrm{Tb}^{3+}$-containing oxide glasses which show the largest Faraday rotation angle among rare-earth-containing glasses, and is comparable to the value for EuSe single crystal. (C) 2001 American Institute of Physics.

[DOI: $10.1063 / 1.1339217$ ]

\section{INTRODUCTION}

The Faraday effect is applicable to many devices in the field of optoelectronics such as an optical isolator, an optical switch, an optical circulator, an optical memory, and so forth. Recent advancement in fabrication of laser diodes with a wavelength corresponding to visible to ultraviolet range requires a Faraday rotator which works efficiently in such a wavelength region. One candidate for that purpose is inorganic glass containing a large amount of rare-earth ions. As indicated by many researchers, ${ }^{1-15}$ rare-earth-containing oxide and fluoride glasses exhibit Faraday rotation in the visible region. The magnitude of Faraday rotation angle increases monotonically with a decrease in the wavelength, and this relationship is described well in terms of the single oscillation model derived from a theory of Van Vleck and $\mathrm{Hebb}^{16}$ for a paramagnetic solid. As argued by Shafer and Suits, ${ }^{3}$ the Faraday rotation angle of rare-earth-containing glasses is determined by probability and wavelength of $4 f-5 d$ transitions as well as magnetic susceptibility of each rare-earth ion. Since the magnetic susceptibility of glass depends on the content of rare-earth ion and the transition wavelength is significantly affected by ligand field strength around a rare-earth ion, the Faraday rotation angle at a discretionary wavelength can be readily changed by varying the glass composition. ${ }^{13,14}$ Nonetheless, the Verdet constant, i.e., Faraday rotation angle per unit length of light path and unit external magnetic field, is not so large compared with ferromagnetic or ferrimagnetic materials like rare-earth iron garnets. ${ }^{17-19}$ This is because the superexchange interaction

\footnotetext{
${ }^{a)}$ Electronic mail: katsu@ipc.kit.ac.jp
}

among rare-earth ions in glasses is generally very small; the rare-earth-containing glass shows paramagnetism even at very low temperatures like $1 \mathrm{~K}$ or so. ${ }^{4}$

Another promising material applicable to Faraday effect devices in the visible range is a semimagnetic semiconductor such as $(\mathrm{Cd}, \mathrm{Mn}) \mathrm{Te}^{20,21}$ It is known that a large Zeeman splitting in semimagnetic semiconductors leads to a large Faraday effect. For instance, $\mathrm{Cd}_{0.24} \mathrm{Mn}_{0.76} \mathrm{Te}$ thin film prepared by the ionized-cluster beam method exhibits a Verdet constant of about $-0.2 \mathrm{deg} / \mathrm{cm} \mathrm{Oe}$, which brings about magneto-optical figure of merit larger than $45 \mathrm{deg} / \mathrm{dB}$ that is required for practical application to an optical isolator, when the wavelength is longer than about $650 \mathrm{~nm} .^{22}$ Additional effect to enhance the Faraday rotation angle is possibly realized when the microcrystals of semimagnetic semiconductor are embedded in a transparent thin film. Because the quantum confinement effect in a microcrystalline semiconductor leads to an increase of oscillator strength, the enhancement of Faraday effect may be caused by the increased oscillator strength of microcrystals in such a composite material. ${ }^{23} \mathrm{In}$ addition, the dielectric constant of matrix in the composite inevitably has influence on the Faraday rotation angle obtained for the composite material. ${ }^{24}$ Several studies have been done concerning the magneto-optical properties of composite thin films in which microcrystalline semimagnetic semiconductors as well as metals are embedded. ${ }^{25-27}$ In the case of semimagnetic semiconductor-embedded thin films, the wavelength dependence of the Faraday rotation angle manifests a blue-shift due to the quantum size effect. ${ }^{27}$

$\mathrm{EuS}$ is one of the semimagnetic semiconductors, and possesses a variety of interesting magnetic properties. Although stoichiometric EuS exhibits transition between ferromagnetic and paramagnetic phases at $16.6 \mathrm{~K}$, incorporation 
of trivalent rare-earth ions such as $\mathrm{Gd}^{3+}$ into $\mathrm{EuS}$ brings about a drastic increase of Curie temperature because the number density of magnetic polarons is increased by the doping of trivalent rare-earth ions. ${ }^{28}$ Also, addition of $\mathrm{SrS}$ into EuS leads to a spin glass phase. ${ }^{29}$ The magneto-optical properties of EuS were measured as well, and the variation of Faraday rotation angle with wavelength was analyzed in terms of the electronic structure of EuS. ${ }^{30-32}$ To our knowledge, however, magneto-optical properties of EuS microcrystals embedded in dielectric thin films have not been reported. In the present investigation, we report successful preparation of EuS microcrystal-embedded oxide thin films by means of an rf sputtering method. We show that in particular, EuS-embedded $\mathrm{TiO}_{2}$ films exhibit a large Faraday effect.

\section{EXPERIMENTAL PROCEDURE}

\section{A. Sample preparation}

EuS microcrystal-embedded oxide thin films were prepared by using an rf sputtering method. $\mathrm{SiO}_{2}, \mathrm{Al}_{2} \mathrm{O}_{3}$, and $\mathrm{TiO}_{2}$ were used as a matrix of the composite film. Bulk $\mathrm{SiO}_{2}$ glass, sintered $\mathrm{Al}_{2} \mathrm{O}_{3}$, and sintered $\mathrm{TiO}_{2}$ were used as sputtering targets. Seven pieces of EuS pellets, prepared by pressing EuS powder under a hydrostatic pressure of about $20 \mathrm{MPa}$, were placed on the target material. The area fraction of EuS pellets on the oxide target was about $47 \%$. The sputtering was carried out under a flow of Ar gas. The gas pressure was $1.0 \times 10^{-2}$ Torr. The rf output power was $100 \mathrm{~W}$.

Commercially available AF45 glass (non-alkali borosilicate glass) was used as a substrate. The substrate was heated at $200{ }^{\circ} \mathrm{C}$, or not heated; two ways were adopted for the treatment of substrate. The deposition time was $25 \mathrm{~h}$. Some of the thin films thus obtained were heat-treated at $450{ }^{\circ} \mathrm{C}$ in an $\mathrm{Ar}$ atmosphere.

\section{B. Measurements}

X-ray diffraction analysis with $\mathrm{Cu} K_{\alpha}$ radiation was performed for as-deposited and heat-treated samples to identify crystalline phases if precipitated. EuS powder, a raw material for preparation of composite films, was also subjected to the $\mathrm{x}$-ray diffraction measurements for comparison with the composite thin film samples.

${ }^{151} \mathrm{Eu}$ Mössbauer effect measurements were carried out for the samples to evaluate the valence state of Eu present in the resultant thin films. The measurements were performed at room temperature using a conventional transmission arrangement (Laboratory Equipment Corporation) with a $1.85 \mathrm{GBq}$ ${ }^{151} \mathrm{Sm}_{2} \mathrm{O}_{3}$ as the $\gamma$-ray source. Calibration of Doppler velocity was done by utilizing Mössbauer spectrum of $\alpha$-Fe foil which was obtained using a $37 \mathrm{MBq}{ }^{57} \mathrm{Co}$ in metallic rhodium as the $\gamma$-ray source. The spectrum of $\mathrm{EuF}_{3}$ was used as a standard for the isomer shift.

The samples were subjected to the measurements of Faraday rotation angle at room temperature. A commercial measurement system for Faraday and Kerr effects (JASCO, Model K-250) was utilized for the measurements. A Xe lamp was used as the light source. The wavelength was varied
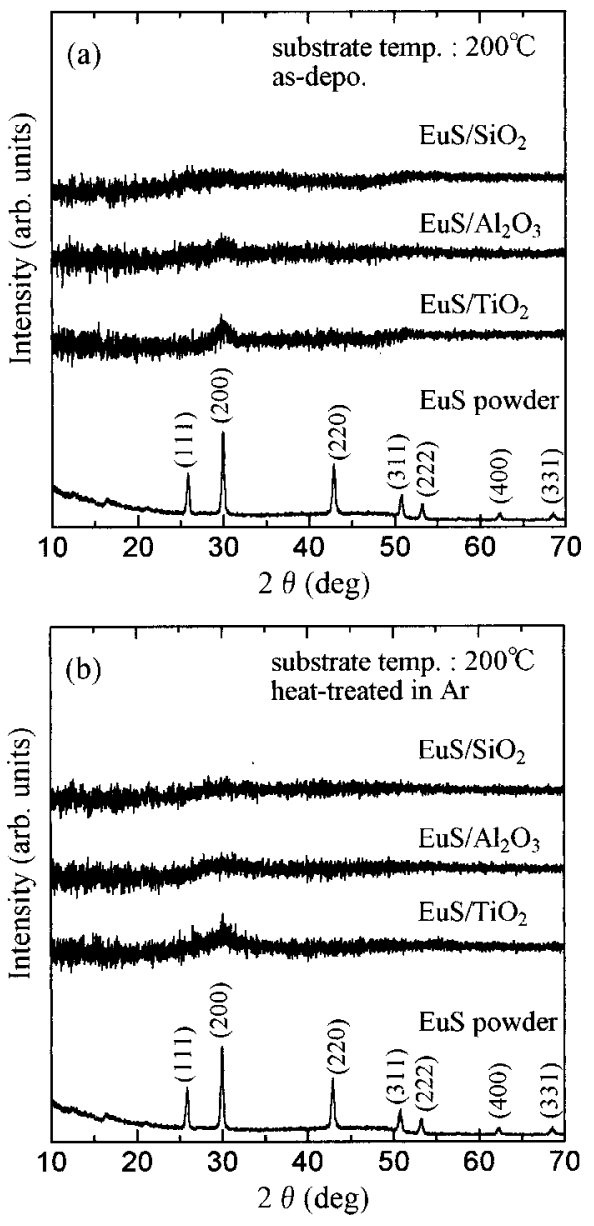

FIG. 1. X-ray diffraction patterns for (a) as-deposited and (b) heat-treated $\mathrm{SiO}_{2}, \mathrm{Al}_{2} \mathrm{O}_{3}$, and $\mathrm{TiO}_{2}$ thin films prepared by heating the substrate at $200{ }^{\circ} \mathrm{C}$ during the sputtering. The x-ray diffraction pattern for EuS powder is also shown for comparison.

from 850 to $400 \mathrm{~nm}$. The external magnetic field was fixed to be $15 \mathrm{kOe}$. The Verdet constant of the thin films was calculated from the Faraday rotation angle, magnetic field, and thickness of the film. The Faraday rotation angle of the thin film was estimated by subtracting the Faraday rotation angle of the substrate from that of the film with the substrate. The thickness of the thin films was estimated from scanning electron micrographs of the samples.

\section{RESULTS}

$\mathrm{X}$-ray diffraction patterns, of as-deposited and heattreated thin films prepared by heating the substrate at $200{ }^{\circ} \mathrm{C}$, are shown in Figs. 1(a) and 1(b), respectively. The x-ray diffraction pattern of EuS powder is also depicted in each of the figures. Precipitation of EuS is observable in both asdeposited and heat-treated $\mathrm{Al}_{2} \mathrm{O}_{3}$ and $\mathrm{TiO}_{2}$ thin films. The intensity of the diffraction line corresponding to the main peak of EuS is higher in the $\mathrm{TiO}_{2}$ than in the $\mathrm{Al}_{2} \mathrm{O}_{3}$ films. In contrast, diffraction lines ascribable to EuS are not observed in as-deposited and heat-treated $\mathrm{SiO}_{2}$ films. Figures 2(a) and 2(b) show the X-ray diffraction patterns of as-deposited and heat-treated thin films for which the substrate was not heated during the sputtering. Precipitation of EuS is evidently confirmed in the as-deposited $\mathrm{Al}_{2} \mathrm{O}_{3}$ and $\mathrm{TiO}_{2}$ thin films, while $\mathrm{EuS}$ is not precipitated in either as-deposited or heat-treated 

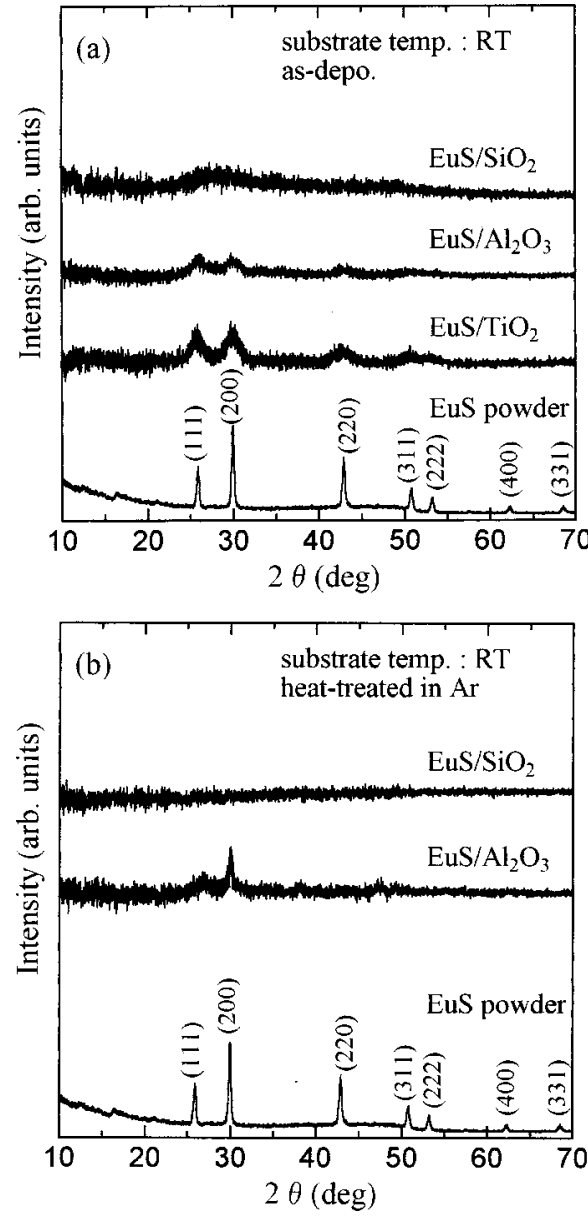

FIG. 2. X-ray diffraction patterns for (a) as-deposited and (b) heat-treated $\mathrm{SiO}_{2}, \mathrm{Al}_{2} \mathrm{O}_{3}$, and $\mathrm{TiO}_{2}$ thin films. The substrate was not heated during the sputtering. The x-ray diffraction pattern for EuS powder is also shown for comparison.

$\mathrm{SiO}_{2}$ films. The EuS phase is also crystallized in heat-treated $\mathrm{Al}_{2} \mathrm{O}_{3}$ film. In the case of heat-treated $\mathrm{TiO}_{2}$ film, an x-ray diffraction pattern could not be obtained because some parts of the film were peeled by the heat treatment. Broad diffraction lines due to EuS are observed in the patterns of $\mathrm{Al}_{2} \mathrm{O}_{3}$ and $\mathrm{TiO}_{2}$ films as shown in Figs. 1 and 2. This suggests that the crystallite size of the EuS precipitated in these films is very small. The results derived from the $\mathrm{x}$-ray diffraction analysis clearly indicate that $\mathrm{Al}_{2} \mathrm{O}_{3}$ and $\mathrm{TiO}_{2}$ are suitable as the matrix material for EuS microcrystalline phaseembedded composite thin films whereas the $\mathrm{SiO}_{2}$ is not fit for that purpose. A similar result was reported for $(\mathrm{Cd}$, $\mathrm{Mn}) \mathrm{Te}$ microcrystal-embedded dielectric films. ${ }^{27}$ When an attempt was made to prepare the film by using $\mathrm{SiO}_{2}$ as the matrix, $(\mathrm{Cd}, \mathrm{Mn}) \mathrm{Te}$ was barely precipitated because of the oxidation of $\mathrm{Mn}^{2+}$. Although the $(\mathrm{Cd}, \mathrm{Mn}) \mathrm{Te}$ microcrystalembedded $\mathrm{SiO}_{2}$ films were successfully prepared by Nasu et al. $^{33}$ the volume fraction of $(\mathrm{Cd}, \mathrm{Mn}) \mathrm{Te}$ microcrystalline phase was so small as 4 vol \%.

Room temperature ${ }^{151} \mathrm{Eu}$ Mössbauer spectra of the asdeposited thin films prepared without the heating of substrate are shown in Fig. 3. The absorption bands centered at around IS $=0 \mathrm{~mm} / \mathrm{s}$ and $-12 \mathrm{~mm} / \mathrm{s}$, where IS represents the isomer

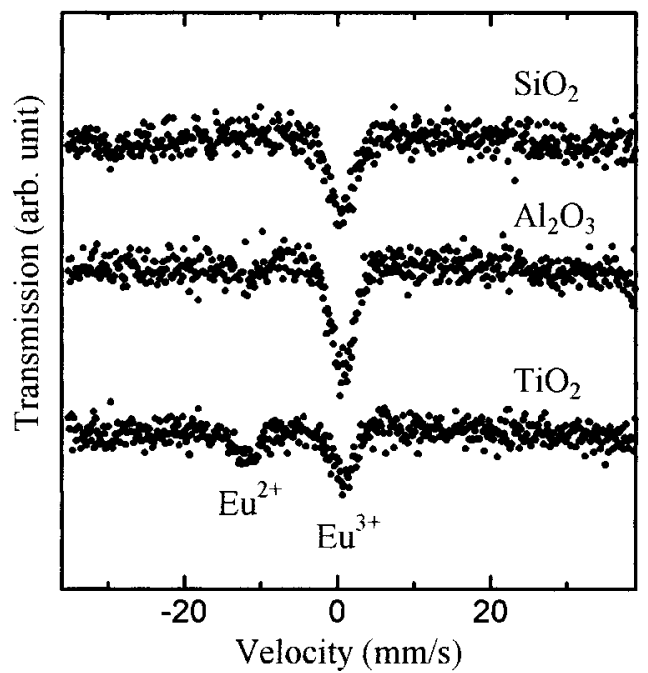

FIG. 3. ${ }^{151} \mathrm{Eu}$ Mössbauer spectra of as-deposited $\mathrm{SiO}_{2}, \mathrm{Al}_{2} \mathrm{O}_{3}$, and $\mathrm{TiO}_{2}$ thin films containing EuS at room temperature. The spectra for the samples prepared without the heating of substrate are shown.

shift, are ascribable to $\mathrm{Eu}^{3+}$ and $\mathrm{Eu}^{2+}$ ions, respectively. The absorption area ratio of $\mathrm{Eu}^{2+}$ to $\mathrm{Eu}^{3+}$ was estimated by fitting Lorentzian curves to the experimental data. The results are summarized in Table I. As pointed out in previous studies ${ }^{34}$ the absorption area ratio is not equal to the molar ratio of $\mathrm{Eu}^{2+}$ to $\mathrm{Eu}^{3+}$ because the temperature dependence of recoilless fraction is different between $\mathrm{Eu}^{2+}$ and $\mathrm{Eu}^{3+}$. Since the Debye temperature for the chemical bond relevant to $\mathrm{Eu}^{2+}$ is lower than that concerning $\mathrm{Eu}^{3+},{ }^{34}$ the molar fraction of $\mathrm{Eu}^{2+}$ in the total number of europium ions is more than the value listed in Table I. Table I indicates that the molar fraction of $\mathrm{Eu}^{2+}$ is the largest for the $\mathrm{TiO}_{2}$ films and the smallest for the $\mathrm{SiO}_{2}$ films. In other words, most of the $\mathrm{Eu}^{2+}$ ions were oxidized during the sputtering when $\mathrm{SiO}_{2}$ was used as the target. This is a phenomenon similar to the oxidation of $\mathrm{Mn}^{2+}$ observed for the $(\mathrm{Cd}, \mathrm{Mn}) \mathrm{Te}-$ embedded $\mathrm{SiO}_{2}$ film described above.

Variation of the Verdet constant with wavelength is shown for $\mathrm{SiO}_{2}$ films in Fig. 4. Figures 4(a) and 4(b) correspond to the $\mathrm{SiO}_{2}$ thin films prepared with and without heating of the substrate, respectively. In both Figs. 4(a) and 4(b), dotted and solid lines denote as-deposited and heat-treated $\mathrm{SiO}_{2}$ films, respectively. The Verdet constant $V$ was evalu-

TABLE I. Absorption area fraction of $\mathrm{Eu}^{2+}$ and $\mathrm{Eu}^{3+}$ in ${ }^{151} \mathrm{Eu}$ Mössbauer spectra for as-deposited $\mathrm{SiO}_{2}, \mathrm{Al}_{2} \mathrm{O}_{3}$, and $\mathrm{TiO}_{2}$ thin films containing EuS.

Absorption area fraction (\%)

\begin{tabular}{clrr} 
Matrix & Substrate temperature $\left({ }^{\circ} \mathrm{C}\right)$ & $\mathrm{Eu}^{2+}$ & $\mathrm{Eu}^{3+}$ \\
\hline $\mathrm{SiO}_{2}$ & 200 & 3 & 97 \\
& not heated & 0 & 100 \\
$\mathrm{Al}_{2} \mathrm{O}_{3}$ & 200 & 14 & 86 \\
& not heated & 20 & 80 \\
$\mathrm{TiO}_{2}$ & 200 & 22 & 78 \\
& not heated & 40 & 60 \\
\hline \hline
\end{tabular}



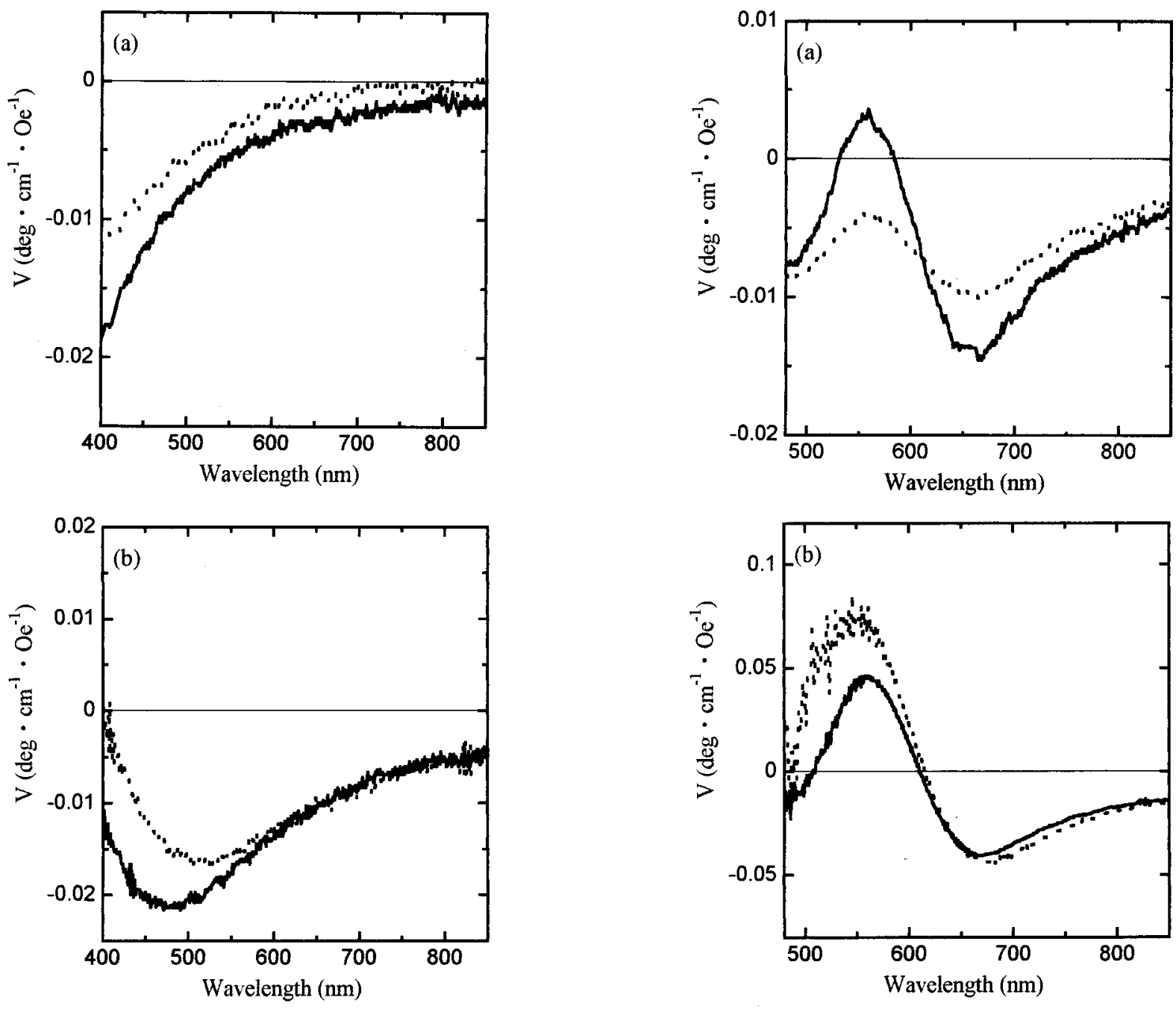

FIG. 4. Dependence of the Verdet constant on wavelength for EuScontaining $\mathrm{SiO}_{2}$ thin films prepared (a) with and (b) without the heating of the substrate. The variation of the Verdet constant for as-deposited (dotted line) and heat-treated (solid line) films is shown.

ated from Faraday rotation angle $\theta$, sample thickness $l$ and external magnetic field $H$ using the following relation:

$$
\theta=V H l .
$$

The Faraday rotation angle due to the diamagnetism of substrate glass was subtracted from the experimental value to obtain the Faraday rotation angle caused by the thin film. The Verdet constant is negative and decreases monotonically with a decrease in wavelength for the $\mathrm{SiO}_{2}$ films prepared with the substrate temperature being $200^{\circ} \mathrm{C}$ [Fig. 4(a)]. A similar tendency is observed for the $\mathrm{SiO}_{2}$ film prepared without heating of the substrate as far as the wavelength range longer than $500 \mathrm{~nm}$ is concerned [Fig. 4(b)].

The dependence of the Verdet constant on the wavelength is shown for EuS microcrystal-embedded $\mathrm{Al}_{2} \mathrm{O}_{3}$ and $\mathrm{TiO}_{2}$ thin films in Figs. 5 and 6, respectively. In these figures, (a) and (b) represent the Verdet constants of thin films prepared with and without heating of substrate during the sputtering, respectively, and dotted and solid lines denote as-deposited and heat-treated films, respectively. The wavelength dispersion of the Verdet constant shown in these figures manifests a similar tendency to each other; the Verdet constant shows a maximum and a minimum at around 550600 and $650-700 \mathrm{~nm}$, respectively. The behavior of the Verdet constant shown in Figs. 5 and 6 is coincident with the wavelength dispersion of the Verdet constant for EuS crystal reported previously. ${ }^{30,31}$ In other words, the Faraday effect of the present EuS microcrystal-doped $\mathrm{Al}_{2} \mathrm{O}_{3}$ and $\mathrm{TiO}_{2}$ thin films is unambiguously brought about by the EuS microcrystalline phases. The Verdet constant of EuS-containing $\mathrm{SiO}_{2}$, $\mathrm{Al}_{2} \mathrm{O}_{3}$, and $\mathrm{TiO}_{2}$ thin films at a wavelength of $700 \mathrm{~nm}$ is summarized in Table II. Verdet constants of rare-earthcontaining glasses are also shown in the table. The magnitude of the Verdet constant for as-deposited $\mathrm{TiO}_{2}$ thin film prepared without the heating of the substrate during the sputtering is $0.15 \mathrm{deg} / \mathrm{cm} \mathrm{Oe}$, which is larger by two orders of magnitude than those of rare-earth-containing glasses. Also, this value is comparable to the magnitude of the Verdet constant for EuSe single crystal $(0.18 \mathrm{deg} / \mathrm{cm}$ Oe at $633 \mathrm{~nm}$ and $0.16 \mathrm{deg} / \mathrm{cm}$ Oe at $666 \mathrm{~nm}) .{ }^{35,36}$ 

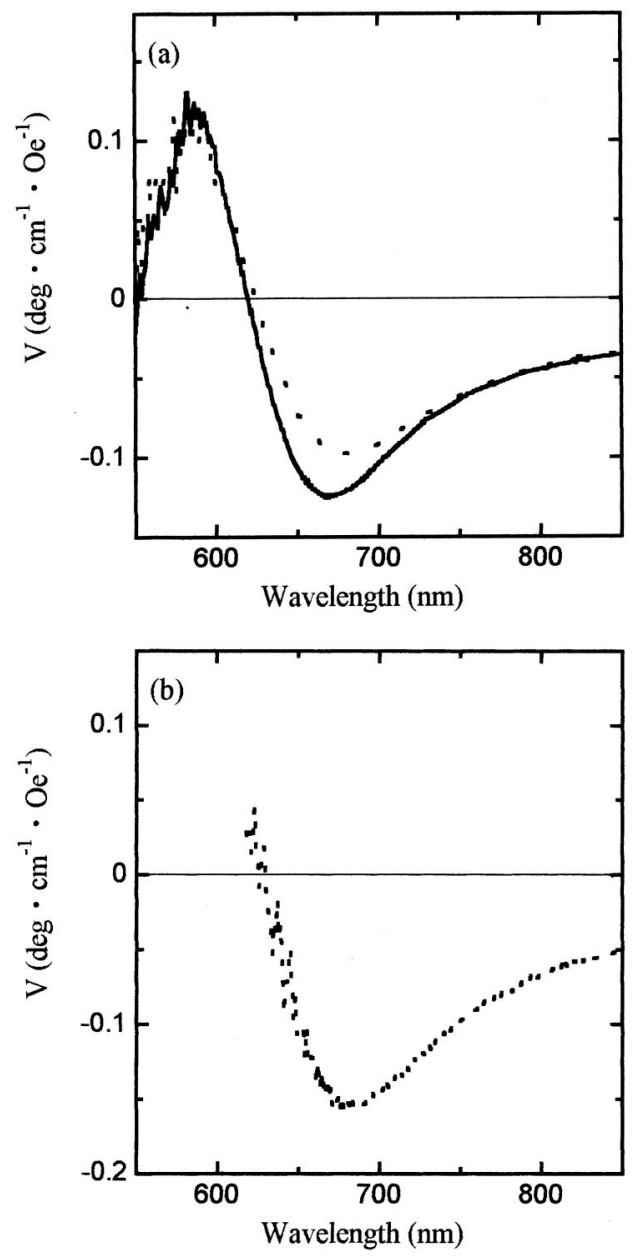

FIG. 6. Dependence of the Verdet constant on wavelength for EuS microcrystal-embedded $\mathrm{TiO}_{2}$ thin films prepared (a) with and (b) without the heating of the substrate. The variation of the Verdet constant for asdeposited (dotted line) and heat-treated (solid line) films is shown.

\section{DISCUSSION}

The results of x-ray diffraction analyses and Mössbauer effect measurements clearly indicate that $\mathrm{TiO}_{2}$ is the most suitable as the host material for the EuS-embedded thin film among the present three kinds of oxides, whereas $\mathrm{SiO}_{2}$ is not appropriate for that purpose. It is speculated that the great

TABLE II. Verdet constant at $700 \mathrm{~nm}$ for $\mathrm{SiO}_{2}, \mathrm{Al}_{2} \mathrm{O}_{3}$, and $\mathrm{TiO}_{2}$ thin films containing EuS. Verdet constants for rare-earth-containing glasses are also shown for comparison. (RT is room temperature.)

\begin{tabular}{lccc}
\hline \hline \multirow{2}{*}{ Matrix } & $\begin{array}{c}\text { Substrate temperature } \\
\left({ }^{\circ} \mathrm{C}\right)\end{array}$ & \multicolumn{2}{c}{ Verdet constant $($ deg/Oe cm $)$} \\
as-deposited & heat-treated \\
\hline $\mathrm{SiO}_{2}$ & 200 & $-2.4 \times 10^{-4}$ & $-2.1 \times 10^{-3}$ \\
& $\mathrm{RT}$ & $-7.8 \times 10^{-3}$ & $-7.8 \times 10^{-3}$ \\
$\mathrm{Al}_{2} \mathrm{O}_{3}$ & 200 & $-7.9 \times 10^{-3}$ & -0.011 \\
& $\mathrm{RT}$ & -0.041 & -0.035 \\
$\mathrm{TiO}_{2}$ & 200 & -0.091 & -0.10 \\
& $\mathrm{RT}$ & -0.15 & \\
$25 \mathrm{~Tb}_{2} \mathrm{O}_{3} \cdot 75 \mathrm{P}_{2} \mathrm{O}_{5}$ glass & & $-2.5 \times 10^{-3}$ \\
$34 \mathrm{EuO}_{1} \cdot 15 \mathrm{Al}_{2} \mathrm{O}_{3} \cdot 51 \mathrm{~B}_{2} \mathrm{O}_{3}$ glass & \multicolumn{2}{c}{$-4.5 \times 10^{-3}$} \\
\hline \hline
\end{tabular}

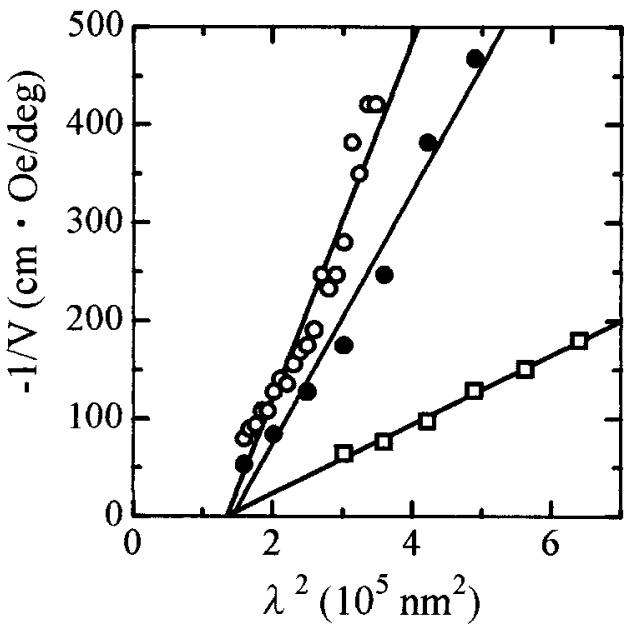

FIG. 7. Relationship between magnitude of the inverse Verdet constant and square wavelength for the $\mathrm{SiO}_{2}$ films. Open circles, closed circles, and open squares denote the as-deposited film prepared by heating the substrate, its heat-treated sample, and as-deposited film prepared without heating of the substrate, respectively. The solid lines were drawn by the least squares method.

glass-forming ability of $\mathrm{SiO}_{2}$ makes the precipitation of crystalline phases difficult, leading to the amorphous films as shown in Figs. 1 and 2. The wavelength dependence of the Verdet constant at a wavelength range longer than $500 \mathrm{~nm}$ for $\mathrm{SiO}_{2}$ films shown in Fig. 4 manifests a tendency similar to those observed for rare-earth-containing glasses; the Verdet constant is negative and the magnitude of the Verdet constant increases with a decrease in wavelength. This tendency is describable in terms of the single oscillator model within the framework of the theory of Van Vleck and Hebb ${ }^{16}$

$$
V^{-1}=\frac{g \mu_{B} c h}{4 \pi^{2} \chi C_{t}}\left(1-\frac{\lambda^{2}}{\lambda_{t}^{2}}\right),
$$

where $\chi$ is the magnetic susceptibility, $g$ is the Landé factor, $\mu_{B}$ is the Bohr magneton, $c$ is the velocity of light, $h$ is the Planck constant, $\lambda$ is the wavelength of incident light, $\lambda_{t}$ is the effective transition wavelength, and $C_{t}$ is the effective transition probability. The relationship between the magnitude of the inverse Verdet constant and the square wavelength is shown for the present $\mathrm{SiO}_{2}$ films in Fig. 7. Open circles, closed circles, and open squares in Fig. 7 denote the as-deposited film prepared by heating the substrate, its heattreated sample, and as-deposited film prepared without heating of substrate, respectively. The linear relationship expressed by Eq. (2) approximately holds for all the samples. In other words, the variation of the Verdet constant with the wavelength is describable in terms of the theory of Van Vleck and Hebb. From the intercept of the lines, the effective transition wavelength was evaluated. The results are summarized in Table III. The effective transition wavelength lies in a range of $360-370 \mathrm{~nm}$. These values are similar to those obtained for $\mathrm{Eu}^{2+}$-containing oxide glasses., ${ }^{3,13,14}$ It is thought that a small amount of $\mathrm{Eu}^{2+}$ ion is present and contributes to the Faraday effect although the absorption due to $\mathrm{Eu}^{2+}$ ion is barely observed in the Mössbauer spectrum because of the small recoilless fraction of $\mathrm{Eu}^{2+}$ as shown in 
TABLE III. Effective transition wavelength $\lambda_{t}$ in Eq. (2) for EuS-containing $\mathrm{SiO}_{2}$ films.

\begin{tabular}{cc}
\hline \hline Preparation condition & Effective transition wavelength (nm) \\
\hline Substrate temperature: $200{ }^{\circ} \mathrm{C}$ & 367 \\
as-deposited & 377 \\
heat-treated & 366 \\
Substrate temperature: $\mathrm{RT}$ & \\
as-deposited & \\
\hline \hline
\end{tabular}

Fig. 3. Also, the Verdet constants at $500 \mathrm{~nm}$ for the $\mathrm{SiO}_{2}$ films, which are about -0.02 to $-0.005 \mathrm{deg} / \mathrm{cm}$ Oe (from -1.2 to $-0.3 \mathrm{~min} / \mathrm{cm} \mathrm{Oe}$ ), are comparable to those reported for rare-earth-containing glasses. ${ }^{1-15}$

A comparison of x-ray diffraction patterns and Mössbauer spectra between $\mathrm{Al}_{2} \mathrm{O}_{3}$ and $\mathrm{TiO}_{2}$ thin films reveals that the amount of EuS precipitated is larger in the $\mathrm{TiO}_{2}$ thin films than in the $\mathrm{Al}_{2} \mathrm{O}_{3}$ thin films when the preparation condition is the same as each other. This is presumably attributable to the difference in ability to form amorphous state between $\mathrm{TiO}_{2}$ and $\mathrm{Al}_{2} \mathrm{O}_{3}$. Kozuka et al. ${ }^{37}$ examined the glassforming region of $\mathrm{TiO}_{2}-\mathrm{RE}_{2} \mathrm{O}_{3}$ and $\mathrm{Al}_{2} \mathrm{O}_{3}-\mathrm{RE}_{2} \mathrm{O}_{3}$ systems, where $\mathrm{RE}$ denotes trivalent rare-earth, by using a twin-roller quenching method. They found that the glass-forming region is somewhat broader for $\mathrm{Al}_{2} \mathrm{O}_{3}-\mathrm{RE}_{2} \mathrm{O}_{3}$ than for $\mathrm{TiO}_{2}-\mathrm{RE}_{2} \mathrm{O}_{3}$ systems. Hence, it is thought that the amount of $\mathrm{Eu}^{2+}$ and $\mathrm{Eu}^{3+}$ dissolved into the amorphous matrix is larger in the $\mathrm{Al}_{2} \mathrm{O}_{3}$ thin films than in the $\mathrm{TiO}_{2}$ thin films in the present case. In other words, precipitation of EuS can take place more readily in the $\mathrm{TiO}_{2}$ films. Furthermore, the $\mathrm{x}$-ray diffraction peaks are higher and become sharper upon heat treatment for films deposited at room temperature than for films deposited at $200^{\circ} \mathrm{C}$, as shown in Figs. 1 and 2. We speculate that this phenomenon is observed because chemical reactions can take place more readily between EuS and oxides to form amorphous matrix phases at the substrates when the substrate temperature is higher.

The $\mathrm{TiO}_{2}$ film possesses the largest magnitude of the Verdet constant among the present three kinds of host materials. This is partly because the amount of EuS precipitated is the largest in the $\mathrm{TiO}_{2}$ film. Nonetheless, it seems that the difference in magnitude of the Verdet constant between $\mathrm{TiO}_{2}$ and $\mathrm{Al}_{2} \mathrm{O}_{3}$ thin films cannot be explained only by the amount of EuS phase. Although the x-ray diffraction patterns in Figs. 1(a) and 2(a) as well as the fraction of $\mathrm{Eu}^{2+}$ shown in Table I indicate that the amount of EuS microcrystals in the asdeposited $\mathrm{Al}_{2} \mathrm{O}_{3}$ film prepared without heating of substrate [Fig. 2(a)] is almost identical to or slightly larger than the amount of EuS precipitated in the as-deposited $\mathrm{TiO}_{2}$ film prepared at the substrate temperature of $200^{\circ} \mathrm{C}$ [Fig. 1(a)], the magnitude of the Verdet constant of the $\mathrm{Al}_{2} \mathrm{O}_{3}$ film is smaller than that of the $\mathrm{TiO}_{2}$ film as shown in Table II. One possibility is the effect of the dielectric constant of the host materials. The Faraday rotation angle of several types of composite materials was calculated theoretically by Abe and Gomi. ${ }^{24}$ According to their calculation, the Faraday rotation angle of a composite material in which spheres are dispersed in a continuous matrix is affected by both Faraday rotation angle and dielectric constant of the dispersed phase and matrix. In the case that magnetic spheres with a dielectric tensor written as

$$
\epsilon=\left(\begin{array}{ccc}
\epsilon & i \gamma & 0 \\
-i \gamma & \epsilon & 0 \\
0 & 0 & \epsilon
\end{array}\right)
$$

are embedded in a matrix with a dielectric constant of $\epsilon_{1}$, the diagonal and off-diagonal elements of the dielectric tensor, $\epsilon_{x x}$ and $\epsilon_{x y}$, for the composite is expressed as follows: ${ }^{24}$

$$
\begin{aligned}
& \epsilon_{x x}=\epsilon_{1}+\frac{3 f \epsilon_{1}\left(\epsilon-\epsilon_{1}\right)}{3 \epsilon_{1}+(1-f)\left(\epsilon-\epsilon_{1}\right)}, \\
& \epsilon_{x y}=\frac{3 i f \epsilon_{1} \gamma}{3 \epsilon_{1}+(1-f)\left(\epsilon-\epsilon_{1}\right)},
\end{aligned}
$$

where $f$ is the volume fraction of the dispersed spheres. The Faraday rotation angle $\Theta$ and the ellipticity angle $\Psi$ of the composite material is written as follows:

$$
\Theta-i \Psi=-i(\pi / \lambda) \epsilon_{x y} / \epsilon_{x x}^{1 / 2} .
$$

The effect of $\epsilon_{1}$, the dielectric constant of the matrix, on the Faraday rotation angle of composite material is complicated as indicated by Eqs. (4)-(6), although an increase of $\epsilon_{1}$ increases the magnitude of imaginary part of $\epsilon_{x y}$ when both $\epsilon_{1}$ and $\epsilon$ are positive real numbers as revealed from Eq. (5), which can contribute to an increase of Faraday rotation angle $\Theta$. It is known that both dielectric constant and refractive index of $\mathrm{TiO}_{2}$ crystal are larger than those of $\mathrm{Al}_{2} \mathrm{O}_{3}$ crystal, ${ }^{38}$ although the matrix phase of the present $\mathrm{TiO}_{2}$ and $\mathrm{Al}_{2} \mathrm{O}_{3}$ thin films is amorphous as shown in Figs. 1 and 2. Hence, the EuS microcrystal-embedded $\mathrm{TiO}_{2}$ film may manifest larger Faraday rotation angle than the $\mathrm{Al}_{2} \mathrm{O}_{3}$ via the effect of large $\epsilon_{1}$ of $\mathrm{TiO}_{2}$ matrix when the amount of EuS is almost the same as each other.

In addition, the large magnitude of the Verdet constant for the $\mathrm{TiO}_{2}$ films is suggestive of the occurrence of quantum confinement effect which leads to the enhancement of Faraday effect in EuS microcrystals. A quantitative analysis of the quantum confinement effect in EuS microcrystals cannot be done at this moment because we have no information about the microstructure of the present films such as the volume fraction and crystallite size of EuS microcrystalline phase. Transmission electron microscopic measurements are required to evaluate the crystallite size of EuS as well as the volume fraction of EuS phase in the $\mathrm{TiO}_{2}$ thin films so that the influence of quantum confinement effect of EuS phase on the Faraday effect can be clarified. In addition, a comparison of the Verdet constant between the present EuS microcrystalembeded $\mathrm{TiO}_{2}$ films and EuS single crystal or thin film is needed. Such a study is in progress.

\section{CONCLUSIONS}

EuS microcrystal-embedded $\mathrm{Al}_{2} \mathrm{O}_{3}$ and $\mathrm{TiO}_{2}$ thin films were successfully prepared by using if sputtering method. Faraday effect due to the $4 f^{7}-4 f^{6} 5 d$ transition of $\mathrm{Eu}^{2+}$ in the EuS microcrystalline phase was clearly observed. In particular, EuS microcrystal-embedded $\mathrm{TiO}_{2}$ thin films exhibit 
large Faraday rotation angle. A comparison of the magnitude of the Verdet constant at a wavelength of $700 \mathrm{~nm}$ among the present thin films and rare-earth-containing oxide glasses reveals that the values for the $\mathrm{TiO}_{2}$ thin films are larger by two orders of magnitude than those of rare-earth-containing glasses. Also, the Verdet constant of the $\mathrm{TiO}_{2}$ thin films is comparable to the value for EuSe single crystal. In contrast, when the target material was $\mathrm{SiO}_{2}$, we could not fabricate EuS microcrystal-embedded films. Instead, amorphous films which showed Faraday effect similar to those of rare-earthcontaining glasses were obtained.

\section{ACKNOWLEDGMENTS}

The authors would like to thank Professor Y. Isozumi and Dr. S. Ito of Radioisotope Research Center, Kyoto University for ${ }^{151} \mathrm{Eu}$ Mössbauer effect measurements. This work was financially supported by Kinki-chiho Invention Center.

${ }^{1}$ C. B. Rubinstein, S. B. Berger, L. G. Van Uitert, and W. A. Bonner, J. Appl. Phys. 35, 2338 (1964).

${ }^{2}$ S. B. Berger, C. B. Rubinstein, C. R. Kurkjian, and A. W. Treptow, Phys. Rev. 133, A723 (1964).

${ }^{3}$ M. W. Shafer and J. C. Suits, J. Am. Ceram. Soc. 49, 261 (1966).

${ }^{4}$ J. Schoenes, E. Kaldis, W. Thöni, and P. Wachter, Phys. Status Solidi A 51, 173 (1979)

${ }^{5}$ T. Izumitani, in Glass Handbook, edited by S. Sakka, T. Sakaino, and K. Takahashi (Asakura Shoten, Tokyo, 1975), p. 972.

${ }^{6}$ V. Letellier, A. Seignac, A. Le Floch, and M. Matecki, J. Non-Cryst. Solids 111, 55 (1989)

${ }^{7}$ G. T. Petrovskii, I. S. Edelman, T. V. Zarubina, A. V. Malakhovskii, V. N. Zabluda, and M. Yu. Ivanov, J. Non-Cryst. Solids 130, 35 (1991).

${ }^{8}$ J. T. Kohli and J. E. Shelby, Phys. Chem. Glasses 32, 109 (1991).

${ }^{9}$ J. T. Kohli, Key Eng. Mater. 94-95, 125 (1994).

${ }^{10}$ D. R. MacFarlane, C. R. Bradbury, P. J. Newman, and J. Javorniczky, J. Non-Cryst. Solids 213-214, 199 (1997).

${ }^{11}$ J. Qiu, K. Tanaka, N. Sugimoto, and K. Hirao, J. Non-Cryst. Solids 213214, 193 (1997).

${ }^{12}$ J. Qiu, K. Tanaka, and K. Hirao, J. Am. Ceram. Soc. 80, 2696 (1997).

${ }^{13}$ K. Tanaka, K. Fujita, N. Soga, J. Qiu, and K. Hirao, J. Appl. Phys. 82, 840 (1997).
${ }^{14}$ K. Tanaka, K. Fujita, N. Matsuoka, K. Hirao, and N. Soga, J. Mater. Res. 13, 1989 (1998).

${ }^{15}$ K. Tanaka, N. Tatehata, K. Fujita, K. Hirao, and N. Soga, J. Phys. D 31, 2622 (1998).

${ }^{16}$ J. H. Van Vleck and M. H. Hebb, Phys. Rev. 46, 17 (1934).

${ }^{17}$ J. F. Dillon, Jr., J. Appl. Phys. 39, 922 (1968).

${ }^{18}$ H. Takeuchi, Jpn. J. Appl. Phys. 14, 1903 (1975).

${ }^{19}$ T. Okuda, T. Katayama, H. Kobayashi, N. Kobayashi, K. Satoh, and H. Yamamoto, J. Appl. Phys. 67, 4944 (1990).

${ }^{20}$ J. A. Gaj, R. R. Galazka, and M. Nawrocki, Solid State Commun. 25, 193 (1978).

${ }^{21}$ N. Kullendorff and B. Hok, Appl. Phys. Lett. 46, 1016 (1985).

${ }^{22}$ T. Koyanagi, K. Matsubara, H. Takaoka, and T. Takagi, J. Appl. Phys. 61, 3020 (1987).

${ }^{23}$ Y. Oka, J. Magn. Soc. Jpn. 17, 869 (1993).

${ }^{24}$ M. Abe and M. Gomi, Jpn. J. Appl. Phys., Part 1 23, 1580 (1984).

${ }^{25}$ M. Abe, M. Gomi, and F. Yokoyama, J. Appl. Phys. 57, 3909 (1985).

${ }^{26}$ T. Imamura, K. Ohmori, K. Yamaguchi, and T. Fujii, in Proceedings of the Sixth International Conference on Ferrites, edited by T. Yamaguchi and M. Abe (The Japan Society of Powder and Powder Metallurgy, Tokyo, 1992), p. 1659.

${ }^{27}$ Y. H. Lee, T. Koyanagi, H. Noda, H. Anno, H. Ohmoto, and K. Matsubara, in Proceedings of the Sixth International Conference on Ferrites, edited by T. Yamaguchi and M. Abe (The Japan Society of Powder and Powder Metallurgy, Tokyo, 1992), p. 1655.

${ }^{28}$ R. J. Gambino, P. Fumagalli, R. R. Ruf, T. R. McGuire, and N. Bojarczuk, IEEE Trans. Magn. 28, 2973 (1992), and references therein.

${ }^{29}$ H. Maletta and P. Convert, Phys. Rev. Lett. 42, 108 (1979).

${ }^{30}$ J. Ferre, B. Briat, C. Paparoditis, S. Pokrzywnicki, and R. Suryanarayanan, Solid State Commun. 11, 1173 (1972).

${ }^{31}$ T. Mitani, M. Ishibashi, and T. Koda, J. Phys. Soc. Jpn. 38, 731 (1975).

${ }^{32}$ C. E. T. Gonçalves de Silva and R. M. Ribeiro, Solid State Commun. 15, 841 (1974).

${ }^{33}$ H. Nasu, M. Hayashi, J. Matsuoka, K. Kamiya, K. Tanaka, and K. Hirao, Jpn. J. Appl. Phys., Part 2 34, L440 (1995).

${ }^{34}$ J. M. D. Coey, A. McEvoy, and M. W. Shafer, J. Non-Cryst. Solids 43, 387 (1981).

${ }^{35}$ J. C. Suits and B. E. Argyle, J. Appl. Phys. 36, 1251 (1965).

${ }^{36}$ J. C. Suits, B. E. Argyle, and M. J. Freiser, J. Appl. Phys. 37, 1391 (1966).

${ }^{37}$ H. Kozuka, R. Ota, and N. Soga, J. Soc. Mater. Sci. Jpn. 35, 73 (1986).

${ }^{38}$ For instance, W. D. Kingery, H. K. Bowen, and D. R. Uhlmann, Introduction to Ceramics, Second Edition (Wiley, New York, 1976), pp. 662 and 933 . 